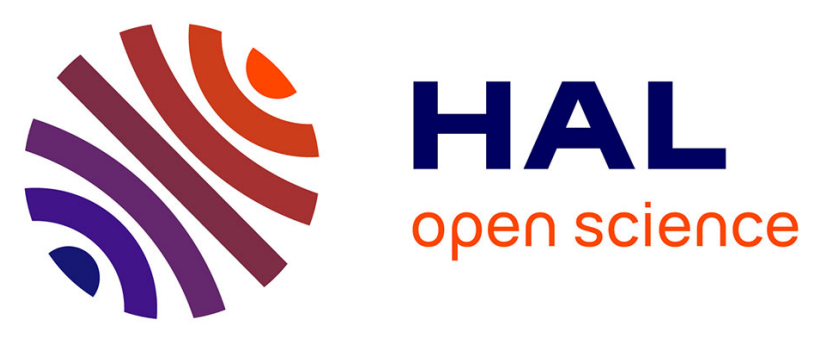

\title{
Management of gastric neuro-endocrine tumours in a large French national cohort (GTE).
}

Sylvain Manfredi, Thomas Walter, Eric Baudin, Philippe Ruszniewski, Thierry Lecomte, Anne-Pascale Laurenty, Bernard Goichot, Vincent Rohmer, Guillaume Roquin, Oana-Zvetlana Cojocarasu, et al.

\section{To cite this version:}

Sylvain Manfredi, Thomas Walter, Eric Baudin, Philippe Ruszniewski, Thierry Lecomte, et al.. Management of gastric neuro-endocrine tumours in a large French national cohort (GTE).. Endocrine, 2017, 57 (3), pp.504-511. 10.1007/s12020-017-1355-9 . hal-01576810

\section{HAL Id: hal-01576810 https://u-bourgogne.hal.science/hal-01576810}

Submitted on 24 Aug 2017

HAL is a multi-disciplinary open access archive for the deposit and dissemination of scientific research documents, whether they are published or not. The documents may come from teaching and research institutions in France or abroad, or from public or private research centers.
L'archive ouverte pluridisciplinaire HAL, est destinée au dépôt et à la diffusion de documents scientifiques de niveau recherche, publiés ou non, émanant des établissements d'enseignement et de recherche français ou étrangers, des laboratoires publics ou privés. 
Management of gastric neuro-endocrine tumours in a large French national cohort (GTE)

Sylvain Manfredi ${ }^{1}$, Thomas Walter ${ }^{2}$, Eric Baudin $^{3}$, Romain Coriat ${ }^{4}$, Philippe Ruszniewski $^{5}$, Thierry Lecomte ${ }^{6}$, Anne-Pascale Laurenty ${ }^{7}$, Bernard Goichot ${ }^{8}$, Vincent Rohmer $^{9}$, Guillaume Roquin ${ }^{10}$, Oana-Zvetlana Cojocarasu ${ }^{11}$, Catherine LombardBohas $^{2}$, Côme Lepage ${ }^{1}$, Jeff Morcet ${ }^{12}$, Guillaume Cadiot ${ }^{13}$.

1 CHU Dijon, hepato-gastroenterology unit, university of Bourgogne Franche-Comté, INSERM, LNC UMR866, F-21000 Dijon, France.

${ }^{2}$ Hospices Civils de Lyon, Hôpital Edouard Herriot, Département d'Oncologie Médicale, 69437 Lyon cedex 03, France.

${ }^{3}$ Gustave Roussy, Département d'Oncologie Endocrinienne, 94805 Villejuif cedex, France.

${ }^{4}$ Department of Gastroenterology and Digestive Oncology, Cochin Teaching Hospital, Paris Descartes University, Paris, France.

${ }^{5}$ Beaujon Hospital and Paris Diderot University, Clichy, France.

6 CHRU de Tours, service d'Hépato-Gastroenterologie, CNRS, UMR 7292, GICC \& Université Francois-Rabelais, Tours, France.

${ }^{7}$ Department of Medical Oncology, Institut Claudius Regaud, Toulouse, France.

${ }^{8}$ Department of Internal Medicine, Endocrinology and Nutrition, Hôpitaux Universitaires de Strasbourg, Faculté de Médecine, Université de Strasbourg, Strasbourg, France.

${ }^{9}$ Service d'endocrinologie et maladies métaboliques, CHU d'Angers, 4 rue Larrey 49100 Angers, France.

${ }^{10}$ Service d'Hépato-Gastro-Entérologie, CHU Angers, Angers, France.

${ }^{11} \mathrm{CH}$ Le Mans, Le Mans, France.

${ }^{12}$ CIC, Université de Rennes 1, Rennes, France.

${ }^{13}$ Department of Hepato-Gastroenterology and Digestive Oncology, Robert-Debré University Hospital, Reims, France.

\section{Corresponding author}

S. Manfredi, MD, Ph. D. CHU Dijon, hepato-gastroenterology unit, 14 rue Paul Gaffarel, 21000 Dijon, FRANCE.

Tel: + 333802937 50. Fax: +33 380293722

E-mail : sylvain.manfredi@chu-dijon.fr 
Short title: MANAGEMENT OF GASTRIC NEURO-ENDOCRINE TUMORS.

Keywords: gastric neuro-endocrine tumour, treatment, survival, cohort.

Word count: 3535 


\section{Abstract}

Gastric neuro-endocrine tumours (GNETs) are rare. European guidelines for the management of GNETs have been published in 2012. The aim of our survey was to study the management of GNETs registered in the national cohort. A prospective national cohort registers the NETs in France since January 2003. We reviewed all the individual medical reports of GNETS in order to collect data on treatment. Results: 197 GNETs diagnosed between 1964 and 2013 in 20 centres were registered. For 181 cases data were considered complete for our survey. Eighty four tumours were type $1(46.4 \%) ; 5$ types 2 (2.8\%); 52 types $3(28.7 \%)$ and 40 types $4(22.1 \%)$. Types 1 and 2 were first endoscopically managed in respectively $93 \%$ and $60 \%$ of cases, whereas surgery was first done respectively in $45 \%$ and $42 \%$ of types 3 and 4 . Systemic treatment, chemotherapy and/or somatostatin analogue (SSA), was first administered exclusively for types 3 and 4 . Near $3 \%$ of types 1 and $40 \%$ of types 2 received at a time SSA treatment. Five-year survival rates were $98.3 \%, 100 \%, 63.2 \%$ and $31.8 \%$ for types $1,2,3$ and 4 respectively. Conclusion: The great majority of GNETs registered in this national cohort are treated in accordance with the current guidelines. The survival rates we reported must be interpreted with caution, because this cohort registered preferentially selected patients eligible for treatment. The registration of all the GNETs, in particular type 1 considered as benign and type 4 not eligible for specific anti-cancer treatment must be encouraged. 


\section{Introduction}

Neuro-endocrine tumours (NETs) are rare. Of those found in the gastrointestinal tract, $5 \%$ to $15 \%$ occur in the gastric region (1-4) in the registry-based studies and up to $23 \%$ for one large prospective study in Austria (5). Three to four types of gastric NETs (GNETs) have been identified: type $1(70 \%-80 \%)$ are developed in the context of chronic atrophic gastritis (auto-immune type A gastritis and Helicobacter Pylori (Hp)-associated atrophic gastritis), preferentially in women (6); type $2(5 \%-6 \%$ of cases) are associated with Zollinger- Ellison syndrome and more common in the setting of multiple endocrine neoplasia (MEN-1) (7); type $3(14 \%-25 \%$ of cases) are defined as sporadic tumours that occur in the absence of hypergastrinemia $(8,9)$. A new type of GNETs was recently described (10); the type 4 corresponding to poorly differentiated neuroendocrine gastric carcinomas. Prognosis and outcomes are dependant of the tumour type (11): without intervention, the outcome of types 1 and 2 is usually benign, with slow growth and, in some cases, spontaneous stabilization or regression. For types 1 and 2 the specific mortality is very low, closed to $0 \%$. For type 1 GNETs recent mono- or multicentric studies report lymph node metastasis rate of $0 \%$ to $5.9 \%$ and liver metastasis rate of $0 \%$ to $2 \%(8,12-15)$. Metastasis occur in $12 \%$ to $30 \%$ of type 2 GNETs, and in $65 \%$ (liver in about 52\%) of the more aggressive type 3 tumours (16).

European guidelines for the management of GNETs have been published in 2012 (17). For type 1 GNETs a conservative management, in order to avoid inappropriate gastrectomy, is recommended. This management is based on regular endoscopic follow-up with iterative limited endoscopic resection of all tumours. For tumours greater than $1 \mathrm{~cm}$ EUS is recommended to assess wall and lymph node invasion, before polypectomy. Surgery must be reserved to tumour involving submucosa and/or lymph node involvement and/or positive margin on polypectomy specimen. For type 2 GNETs local excision is recommended, preferentially by endoscopy. Type 3 is treated in the same way as gastric adenocarcinomas by 
total gastrectomy with extended lymph node resection in the absence of visceral metastasis, or systemic chemotherapy if surgery is not feasible (types 3 and 4 are considered as a single group in this guideline). The place of somatostatin analogue (SSA) is still debated, especially for types 1 and 2 GNETs.

The aim of our study was to study the management of GNETs registered in the national cohort of NETs and to analyse if this management is in accordance with current guidelines.

\section{Population and methods}

A prospective national cohort from the Group of neuroEndocrine Tumour (GTE cohort) registers the incident and prevalent cases of NETs in France since January 2003 via an e-CRF (electronic case report form). In addition a specific national multidisciplinary organization is implemented since 2009 to offer to all patients with NETs in France a specialized multidisciplinary management involving local and national experts (RENATEN network). The registration of the NETs in the national cohort of the GTE is done via a standardized e-CRF: the variables registered prospectively in the cohort for all NETs are: date of birth, date of diagnosis, sex, functional tumour or not, localization of the primary, histologic classification (WHO 2000 (18) or WHO 2010 (19) or both), stage at diagnosis, localization of metastasis, size and number of tumours, Ki 67 index, chromogranin A level, date of last follow-up, status at the last follow-up (dead, alive with tumour, alive without tumour). The standardization of data collected, the same for all the NETs registered, permit to compare the descriptive characteristics of NETs whatever the organ they involved. For our survey an additional investigation was done: all the individual medical reports were reviewed in order to collect additional data: the type of gastric tumour, endoscopic reports, surgical reports, use of SSA therapy, chemotherapy, other oncologic treatments as radiotherapy, serum 
gastrinemia level. The 2 mixed adenoneuroendocrine carcinoma (MANEC) registered in our cohort were considered as type 4 tumours.

We have studied for our survey all cases of GNETs registered between January 2003 and December 2012. Informed consent was given to all the patients. The study was approved by the scientific committee of the national group for NETs (GTE) and the ethic committee of the university hospital of Rennes, France. The study was supported by a fund from Ipsen Pharma SAS.

Statistical analysis

Quantitative and qualitative data were analysed with chi 2 square test, Fisher exact test, Student test, and Wilcoxon test in a univariate analysis. Survival curves are compared with Log rang test. Statistical analysis was performed using JMP PRO (SAS Institute, Inc, Cary, North Carolina).

\section{Results}

At the end point of our study (31 December 2012) 197 GNETs diagnosed between 1964 and 2013 in 20 centres were collected, corresponding to $4.6 \%$ of all the NETs registered ( $\mathrm{n}=4315$ ) (fig 1). The GNETs were at the fifth level in frequency in our cohort (excluding thyroid, parathyroid and adrenal gland tumours). Fifty two cases $(26.4 \%)$ were diagnosed before the start of the cohort (prevalent cases), 137 (69.5\%) were diagnosed since the start of the cohort (incident cases), and for 8 patients the date of diagnosis was not specified. For 181 cases $(92 \%)$ demographics and tumours characteristics data were available for our survey.

Demographics and tumours characteristics are presented in table 1. Half of the tumours registered corresponded to types 3 or 4 GNETs, respectively $28.7 \%$ and $22.1 \%$, type 2 GNETs were very rare totalizing 5 cases $(2.8 \%)$. Males were predominant for types 2,3 , and 4 GNETs (60\% to $75 \%)$ whereas females were predominant for type 1 GNETs (64\%). All 
the type 1 GNETs occurred on proven atrophic gastritis. $H p$ infection status was not specified for all the cases, so no relationship between $\mathrm{Hp}$ infection-related atrophic gastritis can be studied. In the same way the parietal cell antibody serum level was not available for all the patients. The 5 type 2 GNETs had all a proven gastrinoma localized in the duodeno-pancreatic area. Median age at diagnosis was around 55 years for types 1 and 2 GNETs (respectively 55.8 and 53.6 years old) and was around 60 years for types 3 and 4 GNETs (respectively 58.0 and 65.8 years old) $(p=0.02)$. Tumours were significantly smaller for types 1,2 and 3 GNETs than for type 4 GNETs: median size was $20 \mathrm{~mm}, 25 \mathrm{~mm}, 20 \mathrm{~mm}$ and $50 \mathrm{~mm}, \mathrm{p}<0.0001$ ) respectively. Nearly all type $3(96.1 \%)$ and type 4 (97.4\%) GNETs presented as solitary tumour whereas types 1 and 2 presented as multiple tumours in respectively $34.8 \%$ and $50 \%$ of cases, $\mathrm{p}=0.0004$. Chromogranin $\mathrm{A}$ and gastrinemia levels were poorly available. Chromogranin A level $(\mathrm{N}<98 \mu \mathrm{g} / \mathrm{l})$ was available for only 68 cases $(38 \%)$, the median level

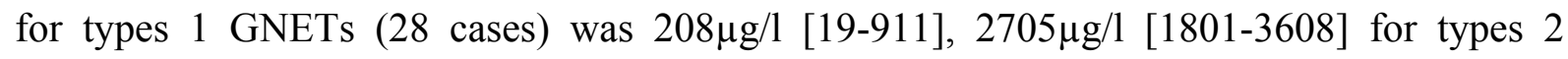

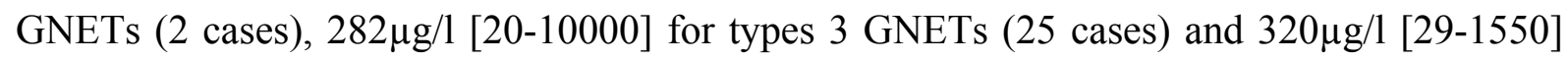
for types 4 GNETs (13 cases). Basal gastrinemia level (N: 13 to $115 \mathrm{ng} / \mathrm{l}$ ) was available for only 53 cases (29\%), median level for types 1 GNETs (27 cases) was 1020ng/l [13-2886], 1690ng/1 [810-3409] for types 2 GNETs (3 cases), 56ng/1 [13-12800] for types 3 GNETs (14 cases) and 129ng/1 [68-1261] for types 4 GNETs ( 8 cases). Types 1 and 2 GNETs were all diagnosed at an early localized stage, whereas $51.9 \%$ of type 3 GNETs and $71.8 \%$ of type 4 GNETs were diagnosed with distant metastasis and respectively $17.3 \%$ and $17.9 \%$ with lymph nodes metastasis $(\mathrm{p}<0.0001)$. For 172 cases $(95.0 \%)$ the data based on WHO 2000 classification were available. All types 1,2 and 3 GNETs corresponded histologically to well differentiated NE tumours or carcinomas whereas all the types 4 , per definition, corresponded to poorly differentiated NE carcinomas. For 126 cases $(69.6 \%)$ the data based on WHO 2010 classification were available. Types 2 and 3 GNETs were all classified as G1 or G2 tumours. 
Types 1 and 2 GNETs were predominantly G1 tumours in 74\% and $60 \%$ of cases respectively, whereas types 3 GNETs were predominantly G2 tumours (72\%). All types 4 GNETs corresponded to G3 tumours, 2 of them where MANECS (Mixed Adenoneuroendocrine Carcinoma). KI67 index was available for 67 cases (37\%). The median percentage was $2 \%$ [1-55] for types 1 GNETs (53 cases) (one well differentiated carcinoma with a KI 67 index at 55\% was classified as type 1 GNET after expert pathology review), 5\% [2-10] for types 2 GNETs (3 cases), 5\% [1-40] for types 3 GNETs (21 cases) and 73\% [1090] for types 4 GNETs (20 cases).

Data about treatment were complete for 141 cases $(78 \%)$. Treatment modalities according to the type of GNETs are presented in table 2. First endoscopically management was achieved for $93 \%$ of type $1,60 \%$ of type $2,39.5 \%$ of type 3 and $3.5 \%$ of type 4 . First endoscopic resection for type 3 GNETs was achieved for small tumours (4 to $20 \mathrm{~mm}$ ) without lymph node or distant metastasis in $87 \%$ of cases. One metastatic type 4 GNETs was first treated by endoscopy in a palliative intent. Surgery was the primary treatment for $40.0 \%$ to $44.7 \%$ of types 2,3 or 4 and $5.8 \%$ of type 1 . Chemotherapy was administered $1^{\text {st }}$ line for $5.3 \%$ of type 3 and $48.3 \%$ of type 4 . No treatment was started for $1.4 \%$ of type 1 and $3.5 \%$ of type 4. SSA was administered $1^{\text {st }}$ line only for type 3 GNETs (7.9\% of cases). Considering all the treatments received $83 \%$ of types 1 GNETs were treated only with endoscopy, $14.5 \%$ required finally surgery and $3 \%$ received SSA. Only $20 \%$ of type 2 GNETs was exclusively treated with endoscopy, finally $60 \%$ required surgery and $40 \%$ received SSA. One quarter of type 3 GNETs were exclusively treated by endoscopy, 58\% required surgery, $21 \%$ required chemotherapy and $21 \%$ received SSA. Types 4 GNETs were treated with more aggressiveness: 59\% required surgery, $66 \%$ chemotherapy and 10\% received SSA. Surgery for types 1 was partial gastrectomy in 7 cases (10\%) and a total gastrectomy in 3 cases (3\%). For type 2 GNETs a partial gastrectomy was done in 3 cases (60\%). For type 3 GNETs a 
partial gastrectomy was done in 12 cases $(31.5 \%)$ and a total gastrectomy in 9 cases $(24 \%)$. For type 4 GNETs a partial gastrectomy was done in 6 cases $(20.5 \%)$ and a total gastrectomy in 10 cases $(34 \%)$.

The mean follow-up was 3 years (range 0 to 45.3 years) for the entire cohort, 4 years (range 0 to 45.3 ) for types $1+2$ and 2 years (range 0 to 14.8 ) for types $3+4$. The vital status at the end of the survey was known for all the patients. Near all the types $1+2$ patients $(97.5 \%)$ were alive at the end of the study and $73.3 \%$ of the types $3+4$. Survival curves of the different types of GNETs are presented in fig 2. The 5-year survival rate decreased with the type of GNETs; types 1 and 2 had an excellent 5-year survival rate (respectively 98.3\% and 100\%) whereas type 3 had a lower 5-year survival rate at $63.2 \%$ and type 4 had the poorer outcome with a 5-year survival rate at $31.8 \%$.

\section{Discussion}

With 197 GNETs registered our cohort is one of the largest one published on management of this disease. Most of the available data about treatment of GNETs came from small monocentric studies or cases reports. One prospective cohort had registered all the NETs in Austria during one year and gave information about 65 incidental GNETs (5). Two population-based studies in UK (20) and Europe (21) reported results about survival of respectively 400 and 380 GNETs registered during 15 and 10 years without detailed data on treatment. Poor data are available about treatment of GNETs from large cohort.

In the national, GTE, NET cohort GNETs represented $4.6 \%$ of all the NETs registered (at the $5^{\text {th }}$ place), and $5 \%$ of the digestive NETs (at the $3^{\text {rd }}$ place after pancreatic NETs (39.7\%) and small bowel NETs (27.4\%)) equally with the NETs of the appendix. Those data are in accordance with a recent review of population-based studies (1) reporting that GNETs represented 5 to $15 \%$ of the digestive NETs, at the $3^{\text {rd }}$ place (equally with NETs of the 
appendix), after small bowel and pancreatic NETs. Data from French or European registries reported a frequency of GNETs range $6.4 \%$ to $20.2 \%(2,21)$. In a prospective national study recording the entire incident digestive NETs during one year in Austria, GNETs was the most frequent digestive NETs and represented $23 \%$ of the cases (5). In our study the registration of all the GNETs is certainly not sufficient: types 3 and 4 GNETs are over-represented with 51\% of the cases, whereas it is usually admitted that types 1 represented 70 to $80 \%$ of the cases (1, 10, 21). Near all the NETs registered in this national cohort (GTE) came from the centres of the RENATEN network where the cases are discussed in specialized multidisciplinary meetings. Types 1 GNETs are probably under registered because considered as benign, easy to treat and to follow-up, and thus probably not discussed in multidisciplinary meetings. In the same way type 4 GNETs not eligible for surgery or chemotherapy are probably not discussed in RENATEN meeting and then not registered.

Even if our study is not a population-based study, with a non-exhaustive registration, the demographics and tumours characteristics we reported are coherent with data from registries. The sex ratios we reported are similar to data published recently in a review (10): type 1 GNETs are more frequent in females (64\%) and types 2,3 and 4 in males $(60 \%$ to $75 \%$ ). In our study type 1 GNETs are diagnosed at a median age of 56 years, tumours are multiple in $35 \%$ of cases, with a median size around $20 \mathrm{~mm}$, with lymph node invasion in $6 \%$ of cases. The median size of type 1 GNETs we reported is bigger than the size usually reported in other studies, consolidating our idea of a recruitment bias of only big tumours that are discussed in multidisciplinary meeting. Type 2 GNETs are diagnosed at a younger age (54 years), more often at a bigger size $(25 \mathrm{~mm})$ and multiple in $50 \%$ of cases. Types 3 and 4 are diagnosed at a more advanced age (58 and 66 years), tumours are bigger for type $4(50 \mathrm{~mm})$, more often solitary, with frequently lymph node metastasis $(17 \%$ and $18 \%)$ or distant 
metastasis $(52 \%$ and $72 \%)$. Those characteristics are similar to data from review (10) or population-based studies $(2,21)$.

The pathologic items useful for the therapeutic decision were available for the majority of the cases of our cohort: items for the WHO 2000 classification were missing for only $5 \%$ of the entire cohort and $2 \%$ for cases registered since 2000 ; items for the WHO 2010 classification were missing for $30 \%$ of the entire cohort and $6 \%$ for the cases registered since 2010. Curiously the KI67 index was clearly mentioned in only $37 \%$ of the pathology records. Items useful but not fundamental are poorly mentioned on pathology and medical reports: chromogranin A and gastrinemia levels were available in only one third of our cases. For type 1 GNETs the knowledge of the presence or absence of Helicobacter pylori infection was insufficient to study the relationship between $\mathrm{Hp}$-associated gastritis and type 1 GNET.

The originality of our work was to focus on the management of GNETs and to analyse the accordance with the available recommendations from ENETS (17) and NANETS (22) guidelines.

For types 1 and 2 conservative management is recommended, based on endoscopy regular follow-up and iterative endoscopic resection. Disease-specific survival was similar in a recent study comparing the 2 strategies: endoscopic follow-up with or without endoscopic resection versus surgical resection for type 1 GNETs (23). Tumour size is an important criteria for the decision of endoscopic resection for types 1 and 2 GNETs but is not the only one. For tumour of big size EUS is recommended to ensure that submucosa is not invaded, before endoscopic resection. In our study whereas sizes of types 1 and 2 GNETs where bigger than reported in previous studies, respectively $93 \%$ and $60 \%$ where first resected endoscopically and finally respectively $14.5 \%$ and $60 \%$ required further surgery. Surgery must be reserved for tumour of big size and/or involving submucosa, or with positive margin after endoscopic resection (24). Systematic endocopic resection of tumours less than $1 \mathrm{~cm}$ had never proven its efficacy and is 
not universally admitted. Treatment with SSA has recently been shown to be effective for types 1 and 2 GNETs (25-28). Somatostatin analogues reduce hypergastrinemia and have a direct antiproliferative effect on ECL cells. Although SSA are not yet recommended for types 1 and 2 GNETs, several case reports or cohort studies have reported reduction or disappearance of tumours treated with SSA $(25,26,29,30)$. Even if SSA are considered as an over-treatment for types 1 and 2 GNETs, it is admitted that for selected cases SSA can be used, especially when endoscopic management is not feasible or not accepted by patients (31). In a recent retrospective multicentre study in Italy, SSA were used in more than one third of patients with type 1 GNETs (30) and then admitted as a valid treatment by the authors. In our cohort near all type 1 GNETs were treated in accordance with guidelines: first endoscopic management (with or without resection), $6 \%$ first surgically managed and $15 \%$ need surgery at a time of their disease history. A small number, of type 1 GNETs (3\%) received SSA. For type 2 GNETs guidelines recommended local excision, preferentially with endoscopy: 60\% were first endoscopically managed and finally $60 \%$ required surgery. Two patients received SSA without official recommendations. Only 5 types 2 GNETs were registered and data about their management cannot be generalized. When analysing all the treatments received, finally $16 \%$ of types 1 and 2 GNETs required surgery as first or subsequent treatment, and SSA therapy was administered in $6 \%$ of all types 1 and 2 GNETs.

For types 3 and 4 the recommendation is to apply the same treatment as for gastric adenocarcinoma: surgery for localized resectable tumours and systemic chemotherapy for metastatic ones. In a recent review by Sato et al. (16), endoscopic resection for selected type 3 GNETs can be an acceptable treatment (well differenciated, $\leq 2 \mathrm{~cm}$, without submucosal invasion). In our cohort we have analysed separately type 3 and type 4 GNETs allowing us to study the place of SSA treatment. Type 3 GNETs were first treated equally with surgery or endoscopy (respectively 40\% and 45\%). Type 3 GNETs in our cohort are all well 
differenciated with a median size of $2 \mathrm{~cm}$ : those characteristics could explain the high rate of endoscopic resection we reported. Chemotherapy was used $1^{\text {st }}$ line in $5 \%$ of cases and SSA in $8 \%$ of cases. Logically only $3.5 \%$ of type 4 GNETs were endoscopically managed, the majority was first treated by surgery (42\%) and 48\% with chemotherapy. No type 4 GNETs received SSA as first treatment. When analysing all the treatments received, nearly $60 \%$ of types 3 and 4 GNETs required surgery. Type 3 GNETs were treated in the great majority by surgery alone (58\%), 21\% received chemotherapy and 21\% SSA. Nearly $50 \%$ of type 4 GNETs were first treated with chemotherapy and finally two-third received chemotherapy. Since the results of the PROMID (32) and the CLARINET (33) studies SSA is a valid treatment for well differentiated G1-2 metastatic NETs of the midgut. In our cohort only $21 \%$ of type 3 GNETs received SSA probably because the majority of cases was diagnosed and treated before the validation of this therapy. SSA was used without valid recommendation in $10 \%$ of type 4 GNETs.

Poor data on survival of GNETs according to the type of tumour are available. Most of studies and reviews (34) reported an excellent 5-year survival for types 1 and 2 GNETs reaching nearly $100 \%$, admitting that those tumours have no or a limited excess risk of death. In our cohort the 5-year survival of types 1 and 2 was nearly $100 \%$, despite 5 -year survival was worse for type 3 GNETs (63\%) and for type 4 (32\%). In the review by O'Toole et al (34) the 5-year survival of types 3 and 4 analysed together was 33\%. In a recent European population-based study (21) 5-year survival was $62 \%$ for well-differentiated GNETs (corresponding to type 3 in our study) and $7.7 \%$ for poorly differentiated (corresponding to type 4 in our study). The 5 -year survival we reported for type 4 is probably over estimated because type 4 GNETs with poorly prognosis treated by best supportive care only are most certainly not registered in our cohort.

\section{Conclusion}


Even if this national cohort is certainly not exhaustive, especially for type 1 considered as benign and some type 4 treated only with best supportive care, the data about treatment we reported are of importance. The great majority of GNETs are treated in accordance with the current guidelines. SSA treatment is rarely administered for types 1 and 2 GNETs, and moderately for type 3 GNETs. The survival rates we reported must be interpreted with caution, in particular for type 4 tumours, because this cohort registered preferentially selected patients eligible for treatment. The registration of all the GNETs, in particular type 1 considered as benign and type 4 not eligible for specific anti-cancer treatment must be encouraged.

\section{Compliance with Ethical Standards}

Funding: The study was supported by a fund from Ipsen Pharma SAS.

Conflict of Interest: All the authors declare any financial or other conflict of interest.

Ethical approval: All procedures performed in studies involving human participants were in accordance with the ethical standards of the institutional and/or national research committee and with the 1964 Helsinki declaration and its later amendments or comparable ethical standards. The study was approved by the scientific committee of the national group for NETs (GTE) and the ethic committee of the university hospital of Rennes, France.

Informed consent: Informed consent was obtained from all individual participants included in the study.

\section{Author contributions:}

S M: drafted and designed the study, recruited patients, and wrote the paper.

T W, G C: recruited patients, revised the manuscript

E B, R C, P R, T L, AP L, B G, V R, G R, OZ C, C LB, C L: recruited patients.

J M: did the statistical analysis 


\section{Aknowledgements:}

All the members of the 2 academics networks involved in this cohort: the GTE ( group for the study of endocrine tumors) and RENATEN (national network for the treatment of endocrine tumors).

All the patients and their family who gave consents for this study. 


\section{References}

1. Fraenkel M, Kim MK, Faggiano A, Valk GD. Epidemiology of gastroenteropancreatic neuroendocrine tumours. Best Pract Res Clin Gastroenterol 2012; 26: 691-703.

2. Lepage C, Bouvier AM, Phelip JM, Hatem C, Vernet C, Faivre J. Incidence and management of malignant digestive endocrine tumours in a well-defined French population. Gut 2004; 53: 549-553.

3. Modlin IM, Lye KD, Kidd M. A 50-year analysis of 562 gastric carcinoids: small tumor or larger problem? Am J Gastroenterol 2004; 99: 23-32.

4. Landry CS, Brock G, Scoggins CR, McMasters KM, Martin RC 2nd. A proposed staging system for gastric carcinoid tumors based on an analysis of 1,543 patients. Ann Surg Oncol 2009; 16: 51-60.

5. Niederle M B, Hackl M, Kaserer K, Niederle B. Gastroenteropancreatic neuroendocrine tumours: the current incidence and staging based on the WHO and European Neuroendocrine Tumour Society classification: an analysis based on prospectively collected parameters. Endocr Relat Cancer 2010; 17: 909-18.

6. Vannella L, Sbrozzi-Vanni A, Lahner E, et al: Development of type I gastric carcinoid in patients with chronic atrophic gastritis. Aliment Pharmacol Ther 2011; 33: 1361-9.

7. Gibril F, Schumann M, Pace A, et al: Multiple endocrine neoplasia type 1 and Zollinger- Ellison syndrome: a prospective study of 107 cases and comparison with 1,009 cases from the literature. Medicine (Baltimore) 2004; 83:43-83.

8. Borch K, Ahren B, Ahlman H, et al: Gastric carcinoids: biologic behavior and prognosis after differentiated treatment in relation to type. Ann Surg 2005; 242: 64-73. 
9. Rindi G, Azzoni C, La Rosa S, et al: ECL cell tumor and poorly differentiated endocrine carcinoma of the stomach: prognostic evaluation by pathological analysis. Gastroenterology 1999; 116: 532-542.

10. Scherübl H, Cadiot G, Jensen R T, Rösch T, Stölzel U, Klöppel G. Neuroendocrine tumors of the stomach (gastric carcinoids) are on the rise: small tumors, small problems? Endoscopy 2010; 42: 664-671.

11. Rappel S, Altendorf-Hofmann A, Stolte M: Prognosis of gastric carcinoid tumours. Digestion 1995; 56: 455-462.

12. Sato Y, Imamura H, Kaizaki Y, et al. Management and clinical outcomes of type I gastric carcinoid patients: retrospective, multicenter study in Japan. Dig Endosc 2014; 26: $377-84$

13. Thomas D, Tsolakis AV, Grozinsky-Glasberg S, Fraenkel M, Alexandraki K, Sougioultzis S, Gross DJ, Kaltsas G. Long-term follow-up of a large series of patients with type 1 gastric carcinoid tumors: data from a multicenter study. Eur J Endocrinol 2013; 168: 185-193.

14. Merola E, Sbrozzi-Vanni A, Panzuto F et al. Type I gastric carcinoids: A prospective study on endoscopic management and recurrence rate. Neuroendocrinology 2012;95: 207-13

15. Chen WC, Warner RR, Ward SC, et al. Management and disease outcome of type I gastric neuroendocrine tumors: the Mount Sinai experience. Dig Dis Sci 2015; 60: 9961003.

16. Sato Y, Hashimoto S, Mizuno K, Takeuchi M, Terai S. Management of gastric and duodenal neuroendocrine tumors. World J Gastroenterol 2016; 22: 6817-28. 
17. Delle Fave G, Kwekkeboom DJ, Van Cutsem, E Rindi G, Kos-Kudla B, Knigge U, Sasano H, Tomassetti P, Salazar R, Ruszniewski P. ENETS Consensus Guidelines for the Management of Patients with Gastroduodenal Neoplasms. Neuroendocrinology 2012; 95: 74-87.

18. Solcia E, Kloppel G, Sobin LH. Histological typing of endocrine tumours. In international histological classification of tumours. $2^{\text {nd }}$ edn, pp 61-68. Berlin Heidelberg: Springer-Verlag, 2000.

19. Sobin LH, Gospodarowicz M, Wittekind Ch, editors. UICC (International Union Against Cancer). TNM classification of malignant tumours. $7^{\text {th }}$ ed. New York: WileyBlackwell. 2009.

20. Lepage C, Rachet B, Coleman MP. Survival from malignant digestive endocrine tumors in England and Wales: a population-based study. Gastroenterology 2007; 132: 899-904.

21. C Lepage, L Ciccolallo, R De Angelis, AM Bouvier, J Faivre, G Gatta and The EUROCARE working group. European disparities in malignant digestive endocrine tumours survival. Int J Cancer 2010; 126: 2928-2934.

22. Kulke MH, Anthony LB, Bushnell DL, de Herder WW, Goldsmith SJ, Klimstra DS, Marx SJ, Pasieka JL, Pommier RF, Yao JC, Jensen RT; North American Neuroendocrine Tumor Society (NANETS). NANETS treatment guidelines: welldifferentiated neuroendocrine tumors of the stomach and pancreas. Pancreas 2010; 39: $735-52$.

23. Gladdy RA, Strong VE, Coit D, Allen PJ, Gerdes H, Shia J, Klimstra DS, Murray FB, Tang LH. Defining surgical indications for type I gastric carcinoid tumor. Ann Surg Oncol 2009; 16: 3154-60. 
24. Ravizza D, Fiori G, Trovato C, Fazio N, Bonomo G, Luca F, Boder L, Pelosi G, Tamayo D, Crosta C. Long-term endoscopic and clinical follow-up of untreated type 1 gastric neuroendocrine tumours. Dig Liver Dis 2007; 39: 537-43.

25. Manfredi S, Pagenault M, de Lajarte-Thirouard AS, Bretagne JF. Type 1 and 2 gastric carcinoid tumors: long-term follow-up of the efficacy of treatment with a slow-release somatostatin analogue. Eur J Gastroenterol Hepatol 2007; 19: 1021-5.

26. Grozinsky-Glasberg S, Kaltsas G, Gur C, Gal E, Thomas D, Fichman S, Alexandraki K, Barak D, Glaser B, Shimon I, Gross DJ. Long-acting somatostatin analogues are an effective treatment for type 1 gastric carcinoid tumours. Eur J Endocrinol 2008; 159: $475-482$.

27. Campana D, Nori F, Pezzilli R, Piscitelli L, Santini D, Brocchi E, Corinaldesi R, Tomassetti P. Gastric endocrine tumors type I: treatment with long-acting somatostatin analogs. Endocr Relat Cancer 2008; 15: 337-342.

28. Khuroo MS, Khuroo MS, Khuroo NS. Treatment of type I gastric neuroendocrine tumors with somatostatin analogs. J Gastroenterol Hepatol 2010; 25: 548-54.

29. Tomassetti P, Migliori M, Caletti GC, Fusaroli P, Corinaldesi R, Gullo L. Treatment of type II gastric carcinoid tumors with somatostatin analogues. N Engl J Med 2000; 343: $551-4$

30. Campana D, Ravizza D, Ferolla P, Faggiano A, Grimaldi F, Albertelli M, Berretti D, Castellani D, Cacciari G, Fazio N, Colao A, Ferone D, Tomassetti P. Clinical management of patients with gastric neuroendocrine neoplasms associated with chronic atrophic gastritis: a retrospective, multicentre study. Endocrine 2016; 51: 131-9.

31. Massironi S, Sciola V, Pia Spampatti M, Peracchi M, Conte D. Gastric carcinoids: Between underestimation and overtreatment. World J Gastroenterol 2009; 15: 21772183. 
32. Rinke A, Müller HH, Schade-Brittinger C, Klose KJ, Barth P, Wied M, Mayer C, Aminossadati B, Pape UF, Bläker M, Harder J, Arnold C, Gress T, Arnold R; PROMID Study Group. Placebo-controlled, double-blind, prospective, randomized study on the effect of octreotide LAR in the control of tumor growth in patients with metastatic neuroendocrine midgut tumors: a report from the PROMID Study Group. J Clin Oncol. 2009; 27: 4656-63.

33. Caplin ME, Pavel M, Ćwikła JB, Phan AT, Raderer M, Sedláčková E, Cadiot G, Wolin EM, Capdevila J, Wall L, Rindi G, Langley A, Martinez S, Blumberg J, Ruszniewski P; CLARINET Investigators. Lanreotide in metastatic enteropancreatic neuroendocrine tumors. N Engl J Med 2014; 371: 224-33.

34. O'Toole D, Delle Fave G, Tensen RT. Gastric and duodenal neuroendocrine tumours. Best Pract Res Clin Gastroenterol 2012; 26: 719-35. 


\section{Figure legends:}

Fig 1: distribution of NETs in the French national cohort

Fig 2: survival curves 
Table 1: demographic and tumours characteristics of the 181 gastric NETs

\begin{tabular}{|c|c|c|c|c|c|}
\hline $\mathrm{n}$ & $\begin{array}{l}\text { Type1 } \\
84\end{array}$ & $\begin{array}{l}\text { Type } 2 \\
5\end{array}$ & $\begin{array}{c}\text { Type } 3 \\
52\end{array}$ & $\begin{array}{c}\text { Type } 4 \\
40\end{array}$ & $\mathrm{p}$ \\
\hline Frequency, \% (n) & 46.4 & 2.8 & 28.7 & 22.1 & \\
\hline Males, \% & 35.7 & 60.0 & 63.5 & 75.0 & 0.0002 \\
\hline $\begin{array}{l}\text { Median age at diagnosis, } y \\
\text { [min-max }]\end{array}$ & $\begin{array}{c}55.8 \\
{[9.6-84.8]}\end{array}$ & $\begin{array}{c}53.6 \\
{[28.0-60.5]}\end{array}$ & $\begin{array}{c}58.0 \\
{[19.3-81.4]}\end{array}$ & $\begin{array}{c}65.8 \\
{[11.1-89.2]}\end{array}$ & 0.02 \\
\hline $\begin{array}{l}\text { Size }<1 \mathrm{~cm}, \% \\
\text { NA, } n\end{array}$ & $\begin{array}{c}47.6 \\
9\end{array}$ & $\begin{array}{c}20.0 \\
1\end{array}$ & $\begin{array}{c}17.4 \\
6\end{array}$ & $\begin{array}{l}2.8 \\
4\end{array}$ & $<0.0001$ \\
\hline $\begin{array}{l}\text { Median size, } \mathrm{mm} \\
{[\min -\max ]}\end{array}$ & $\begin{array}{c}20 \\
{[2-45]}\end{array}$ & $\begin{array}{c}25 \\
{[7-62]}\end{array}$ & $\begin{array}{c}20 \\
{[4-160]}\end{array}$ & $\begin{array}{c}50 \\
{[4-200]}\end{array}$ & $<0.0001$ \\
\hline $\begin{array}{l}\text { Solitary tumour, } \% \\
\text { NA, } \mathrm{n} \\
\text { Median number when } \\
\text { multiple [min-max] }\end{array}$ & $\begin{array}{c}65.2 \\
15 \\
8 \\
{[2-20]}\end{array}$ & $\begin{array}{c}50.0 \\
1 \\
-\end{array}$ & $\begin{array}{c}96.1 \\
1 \\
-\end{array}$ & $\begin{array}{c}97.4 \\
1 \\
-\end{array}$ & 0.0004 \\
\hline $\begin{array}{l}\text { Stage at diagnosis, \% } \\
\text { Localized } \\
\text { Nodes metastasis } \\
\text { Distant metastasis }\end{array}$ & $\begin{array}{r}94.1 \\
5.9 \\
-\end{array}$ & $\begin{array}{c}100 \\
- \\
-\end{array}$ & $\begin{array}{l}30.8 \\
17.3 \\
51.9\end{array}$ & $\begin{array}{l}10.3 \\
17.9 \\
71.8\end{array}$ & $<0.0001$ \\
\hline $\begin{array}{l}\text { Differentiation, } \% \\
\text { WHO } 2000(\mathbf{n}=\mathbf{1 7 2})\end{array}$ & 79 & 5 & 48 & 40 & \\
\hline $\begin{array}{l}\text { Well differenciated } \\
\text { tumour }\end{array}$ & 50.6 & 40.0 & 2.1 & - & $<0.0001$ \\
\hline $\begin{array}{l}\text { Well differenciated } \\
\text { carcinoma }\end{array}$ & 49.4 & 60.0 & 97.9 & - & \\
\hline $\begin{array}{l}\text { Poorly differenciated } \\
\text { carcinoma }\end{array}$ & - & - & - & $100 *$ & \\
\hline WHO $2010(n=126)$ & 58 & 4 & 36 & 28 & \\
\hline Grade 1 & 74.1 & 60.0 & 27.8 & - & $<0.0001$ \\
\hline Grade 2 & 24.1 & 40.0 & 72.2 & - & \\
\hline Grade 3 & 1.7 & 0 & - & $100^{*}$ & \\
\hline
\end{tabular}

NA: Not Available, * 2 MANECs 
Table 2: first and further treatments according to the type of GNETs

\begin{tabular}{lcccc}
\hline $\mathrm{n}=141$ & $\begin{array}{r}\text { Type1 } \\
\mathrm{n}=69\end{array}$ & $\begin{array}{c}\text { Type 2 } \\
\mathrm{n}=5\end{array}$ & $\begin{array}{r}\text { Type 3 } \\
\mathrm{n}=38\end{array}$ & $\begin{array}{r}\text { Type 4 } \\
\mathrm{n}=29\end{array}$ \\
\hline First treatment \% & & & & \\
$\quad$ Endoscopy & 92.8 & 60.0 & $39.5^{* *}$ & $\begin{array}{c}3.5 * * * \\
\text { Surgery }\end{array}$ \\
Chemotherapy & 5.8 & 40.0 & 44.7 & 41.5 \\
No treatment & - & - & 5.3 & 48.3 \\
SSA & 1.4 & - & - & 3.5 \\
All treatments \% & - & - & 7.9 & - \\
Endoscopy & 82.6 & 20.0 & $23.7 * *$ & $3.5 * * *$ \\
Surgery & 14.5 & 60.0 & 57.9 & 58.6 \\
Chemotherapy & - & - & 21.1 & 65.5 \\
SSA & 2.9 & $40.0 *$ & 21.1 & 10.3 \\
\hline
\end{tabular}

SSA: somatostatin analogue, $*$ surgery + SSA, ** tumour size 4 to $20 \mathrm{~mm}$, grade 1 or 2 , $86.7 \%$ localized, $13.3 \%$ metastatic, $* * * 1$ metastatic case treated palliatively 
Fig 1

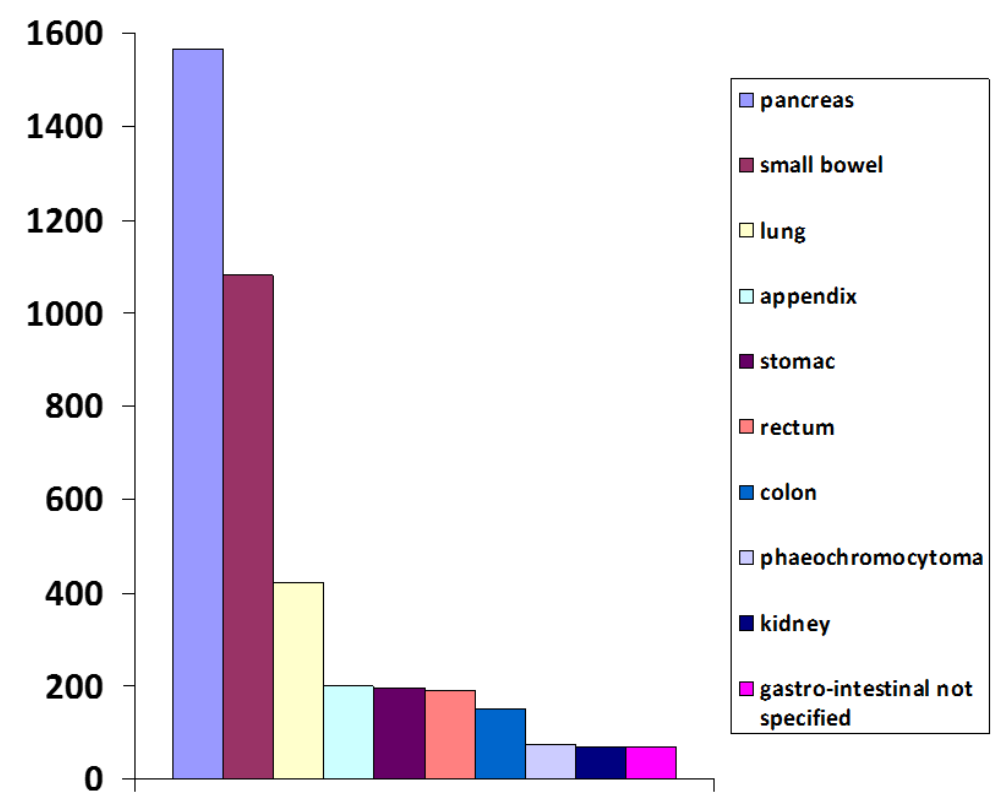


Fig 2

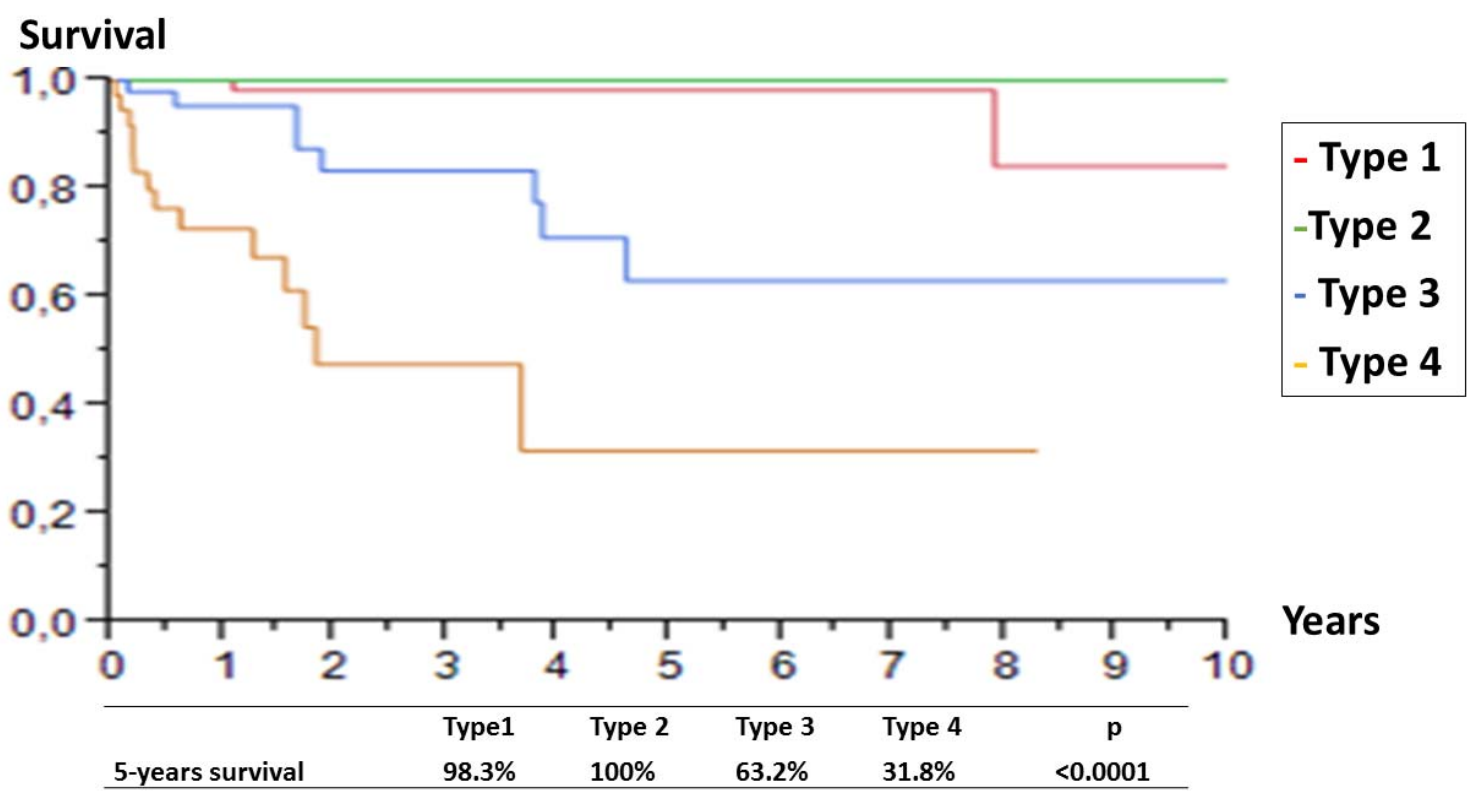

